\title{
SOBRE LAS NUMERACIONES DE LOS REYES DE GASTILLA
}

Los cronistas castellanos y leoneses anteriores a Alfonso el Sabio se valen de sobrenombres para diferenciar a los reyes homónimos, y también para caracterizar y glorificar a los monarcas. Con el sobrenombre, que unas veces recuerda hazañas memorables o sucesos decisivos y otras destaca rasgos tipificadores, se da por entero y de una vez, aunque borrosamente y con una sola perspectiva, la persona o el reinado del monarca.

En este sentido la Primera crónica general señala un importante cambio de sistema. Alfonso el Sabio ${ }^{1}$ introduce el uso del numeral para distinguir a los reyes de igual nombre. Práctica que se generaliza en los primeros años del siglo xrv, y que se ha seguido utilizando hasta ahora.

Los sobrenombres, convertidos en fórmulas cristalizadas, coexisten con los numerales reforzando la diferenciación. Aquí agrupamos los principales:

Alfonso I: el Católico. Alfonso II: el Casto. Alfonso III: el Magno. Alfonso IV: el Monje, el Ciego. Alfonso V: el Noble. Alfonso VI: el que ganó Toledo, el que fue monge en Sant Fagunt, el Bravo, el de las particiones. Alfonso VII: el Emperador, el rey de España. Alfonso VIII: el Bueno, el Noble, el que perdió la batalla de Alarcos y ganó la de las Navas de Tolosa. Alfonso X: el Sabio, el Emperador, el que fue elegido emperador, el que siendo infante ganó el reino de Murcia. Alfonso XI: el Bravo, el Bueno, el Conqueridor, el que venció la batalla de Tarifa, el que ganó la gran batalla de Belamerín.

Fernando I: el Magno, el que ganó Coimbra y Viseo. Fernando III: el Santo, el que ganó la Frontera, el que ganó Sevilla y Córdoba, el que ganó Sevilla y Córdoba y las villas del obispado de Jaén y el reino de Murcia. Fernando IV: el Emplazado, el que ganó Gibraltar y Alcaudete. Fernando V: el Católico.

Sancho I: el Gordo. Sancho II: el que murió sobre Zamora. Sancho III: el Deseado. Sancho IV: el Bravo, el que ganó Tarifa.

1 Por Alfonso el Sabio entiéndase Alfonso y sus colaboradores y continuadores. Véase Ramón Menéndez Pidal (ed.), Primera crónica general, Madrid, 1955 , t. 1, p. xix. 
Enrique I: el que murió niño en Palencia. Enrique II: el Noble, el Viejo. Enrique III: el Bueno, el Doliente2.

Cuando los cronistas se deciden a utilizar el método diferenciador introducido por Alfonso el Sabio, tropiezan con ciertas dificultades. Castilla nace después de una larga serie de reyes asturianos y leoneses. Es un principio, pero a la vez una continuación. Se puede considerar a los monarcas castellanos, o separados de sus antecesores y constituyendo una nueva serie (la castellana), o bien continuando la línea astur-leonesa. Después León y Castilla se unen y se separan en varios momentos, por ello algunos de sus reyes pertenecen por igual a las dos series. De ahí que monarcas con el nombre de Alfonso, de Sancho o de Fernando hayan reinado en Asturias, o en León, o en Castilla, o en León y Castilla:

Alfonso I, Asturias: Alfonso II, Asturias; Alfonso III, León; Alfonso IV, León; Sancho I, León; Alfonso V, León; Fernando I, Castilla y León; Sancho II, Castilla y León; Alfonso VI, Castilla y León; Alfonso VII, Castilla y León; Sancho III, Castilla; Fernando II, León; Alfonso VIII, Castilla; Alfonso IX, León; Fernando III, Castilla y León; Alfonso X, Castilla y León; Sancho IV, Castilla y León; Fernando IV, Castilla y León; Alfonso XI, Castilla y León.

2 Alfonso I.-Don Juan Manuel, Crónica abreviada, ed. Raymond L. Grismer y Mildred B. Grismer, Minneapolis, 1958, p. 112: "Entró en Asturias don Alfon[so] fijo del duc don Pedro de Cantabria al que dixeron Católigo". Historia Silense, ed. Francisco Santos Coco, Madrid, 1921, p. 27: "Igitur Froyla Petri Cantabrorum patricii ducis generosa proles, cum germano fratre Adefonso Catholico atque regni socio arma contra barbaros crebro arripiens. ." Lucas de Tuy, Crónica de España, ed. Julio Puyol, Madrid, 1926, p. 279: "En la hera de sietecientos e setenta e seys Alfonso Cathólico fue elegido por rey del pueblo de los godos".

Alfonso II.-Lucas de Tuy, p. 284: "En la hera de ochocientos y ochenta y ocho, Alfonso Casto y Piadoso, fijo del rey Fruyla, rescibió el regno". Poema de Fernán González, ed. R. Menéndez Pidal en Reliquias de la poesia épica española, Madrid, 1951, copla 126 (p. 5o): "Después reygnó Alfonso, un rey de grand valor, / "el Casto» que dixeron, siervo del Criador". Crónica abreviada, ed. cit. p. 118: "Don Alfonso... éste fue om[n]e muy casto que nun[c]a ovo alegança en su vida a muger". Historia Silense, ed. cit., p. 27: "Qui profecto Adefonsus castus per LII annos castam, pudicam, sobriam ducens vitam..."

Alfonso IIL-Crónica abreviada, ed. cit., p. 122: "Muerto el rey don Hordon[n]o, regnó en pos él su fijo do[n] Alfon[so] al que dixeron Magno". Fernán Pérez de Guzmán, Loores de los claros varones de España, en Cancionero castellano del siglo $x y$, ed. R. Foulché-Delbosc, Madrid, 1912-1915, t. 1, p. 723b: "Don Alfonso el tercero, / que por actos de gran fama / el Magno o Grande se llama". Historia Silense, ed. cit., p. 33: "Cuius rei nuntium Adefonsus magnus, qui casu obeunte patre a palatio aberat, postquam accepit, summa cum festinatione Oveti venit".

Alfonso IV.-Crónica abreviada, ed. cit., p. 130: "Alęaron por rey a don Ordon[n]o, fijo del rey don Alfon[so] el Ciego". Crónica de España, ed. cit., p. 314: "El rey Alfonso, ciego, el octauo año desque començó a reynar murió". Enrique Flórez, Clave historial, Madrid, 1749, p. 164: "Alfonso IV el Monge". 
Los escritores de los siglos xiv, xv y xvi resuelven el problema desde diferentes perspectivas y teniendo en cuenta factores distintos. Cada solución muestra una actitud histórica valiosa para entender la idea que de Castilla tuvo una época o un individuo.

\section{Primera numeración}

Alfonso el Sabio explica así la composición de la Primera crónica general: "mandamos ayuntar quantos libros pudimos auer de istorias en que alguna cosa contassen de los fechos d'Espanna. . . et compu-

Alfonso VI.-Primera crónica general, ed. cit., t. 2, p. 520: "Era este rey don Alífonsso el Sesto de edad de xxx annos et vir meses quando començó a reynar, et regnó xulu annos. Et éste fue el rey don Alffonso el Sesto, et dizíenle por connoscencia de sobrenombre «el rey don Alffonso el Brauo», et aun por otro sobrenombre «el rey don Alífonsso el de las particiones»". Crónica abreviada, ed. cit., p. 165: "El rey don Alfon[so] que ganó Toledo cassó su fija". Crónica del rey don Juan, primero de Castilla e de León, Madrid, 1953, p. 127: "E1 rey don Alfonso fijo del conde don Remón e de la reyna doña Urraca, e nieto del rey don Alfonso que ganó a Toledo".

Alfonso VII.-Poema de Almeria, en Chronica Adefonsi Imperatoris, ed. Luis Sánchez Belda, Madrid, 1950, p. 166: "Dux fuit Imperii cunctorum rex Toletani. / Hic Adefonsus erat, nomen tenet imperatoris". Pablo de Santa María, Las edades del mundo, en Cancionero castellano del siglo xv, ed. cit., t. 2, p. 187: "Tras estos pasados quedó sucesor / aquel don Alfonso que fue enperador, / del qual entonces fue ganada Almería".

Alfonso VIII.-Crónica de los muy altos y esclarecidos don Fernando e doña Isabel, Madrid, 1953, p. 255: "Doña Berenguela, la fija del rey don Alonso de Castilla, el que venció la batalla de las Navas de Tolosa, subcedió en el reyno de Castilla por fin de su hermano".

Alfonso X.-Crónica del rey don Fernando Cuarto, Madrid, 1953, p. 93: "Aquí comienza el reinado del rey don Fernando, fijo del rey don Sancho e nieto del dicho señor rey don Alfonso Emperador". Crónica del rey don Juan el Segundo, Madrid, 1953, p. 277: "Este preclarisimo rey don Juan... fue viznieto del muy excelente rey don Alonso Onceno... e fue descendiente en seteno grado del rey San Luis de Francia e del rey don Alonso Deceno que fue elegido por emperador". Diego de Valera, Doctrinal de principes, en Prosistas castellanos del siglo $x v$, ed. Mario Penna, Madrid, 1959, t. 1, p. 176: "De la justicia del rey don Sancho, fijo del rey don Alfonso el Sabio que fue elegido por enperador".

Alfonso XI.-Crónica del rey don Alfonso Décimo, Madrid, 1953, p. 3: "Este rey don Alfonso [XI], que es llamado Conqueridor". Poema de Alfonso Onceno, ed. F. Janer, Madrid, 1863 , v. 1945: "E pensasen de guardar / a Málaga de cabo a cabo, / que la quería cercar / el rrey don Alfonso el Brauo". Ibid., v. 2147: "El rrey don Alfonso el Bueno / la hueste siempre allegando".

Fernando I.-Doctrinal de príncipes, ed. cit., p. 178: "Del bienaventurado rey don Fernando... que ganó a Coimbra e Viseo".

Fernando III.-Ibid., p. 188: "Del santo e bienaventurado rey don Fernando que ganó Sevilla e Córdova”. Crónica del rey don Alfonso Décimo, ed. cit., p. 3: "Desde el rey don Pelayo... fasta el tiempo que finó el rey don Ferrando que ganó a Sevilla e a Córdoba e las villas del obispado de Jahén e el regno de Murcia”. Crónica del rey don Juan, primero de Castilla e de León, ed. cit., p. 127: "Quiso Dios que después se ayuntasen estos regnos en el rey don Ferrando que ganó a Sevilla e a Córdoba e a la Frontera". 
siemos este libro de todos los fechos que fallarse pudieron della"3. El método alfonsí, que tiende a presentar un panorama total y detallado de la historia de España, consiste en una búsqueda y acumulación exhaustivas de material y en una utilización completa de noticias.

Indica también el Rey Sabio su propósito: dar a conocer el origen de los españoles, y nombrar a las gentes por las que España fue maltrecha; mostrar la nobleza de los godos, y cómo, por el desacuerdo que tuvieron con su señor, España casi entera fue ganada por "los d'Áffrica"; mostrar también cómo los cristianos fueron cobrando la tierra, y el daño que les vino por la partición de los reinos hasta que los "ayuntó Dios"; recordar los reyes que llevaron la reconquista hasta el Mediterráneo, las fechas y la manera; narrar, por último, las proezas de los monarcas y trazar la línea sucesoria indicando "cuémo uinieron unos empós otros fastal nuestro tiempo"4.

Fernando IV.-Las edades del mundo, ed. cit,, p. 188a: "Aquel don Fernando que ovo ganado / la fuerte villa que dizen Gibraltar". Doctrinal de principes, ed. cit., p. 177: "Éste fue padre de don Fernando que murió en Jahén enplazado por los dos hermanos Carvajales que a tuerto mandó matar".

Sancho I.-Crónica del obispo don Pelayo, ed. B. Sánchez Alonso, Madrid 1924, p. 70: "In diebus Fredenandus Rex, filius Sancii Grassi Regis". Crónica abreviada, ed. cit., p. 129: "Esto fazía él por consejo de don[n]a Teresa su muger, que fuera fija del rey don G[arc]ía de Navarra el Tembloso. E ovo en ella un fijo que dixeron don Sancho el Gordo".

Sancho II.-Las edades del mundo, ed. cit., p. $187 a$ : "Aquel rey don Sancho que mató Vellido / estando en Zamora quando la cercó".

Sancho III.-Ibid., p. 187b: "Don Sancho, que fue llamado Deseado, / fue rey después déste, mas poco duró".

Sancho IV.-Crónica del rey don Alfonso Décimo, ed. cit., p. 3: "Las cosas que acaescieron... en tiempo del rey don Sancho su abuelo, el Bravo".

Enrique I.-Crónica de los muy altos y esclarecidos don Fernando $e$ doña Isabel, ed. cit., p. 255: "El rey don Enrique, el que murió niño en Palencia".

Enrique II.-Hernán Pérez de Guzmán, Generaciones y semblanzas, Buenos Aires, 1947, p. 13: "Començaré en don Enrique, el tercero rey de este nombre que en Castilla e en León reinó, e fue nieto del rey don Enrique el Noble, segundo deste nombre".

3 Primera crónica general, ed. cit., t. 1, p. 4.

4 Ibid., p. 4: "Esto fiziemos por que fuesse sabudo el comienço de los espannoles, et de quáles yentes fuera Espanna maltrecha, et que sopiessen las batallas que Hércoles de Grecia fizo contra los espannoles, et las mortandades que los romanos fizieron en ellos, et los destruymientos que les fizieron otrossí los vbándalos et los silingos et los alanos et los sueuos que los aduxieron a seer pocos; et por mostrar la nobleza de los godos et cómo fueron uiniendo de tierra en tierra, uenciendo muchas batallas et conquiriendo muchas tierras, fasta que llegaron a Espanna, et echaron ende a todas las otras yentes, et fueron ellos sennores della; et cómo por el desacuerdo que ouieron los godos con so sennor el rey don Rodrigo, et por la tración que urdió el conde don Yllán et ell arçobispo Oppa passaron los d'Áffrica et ganaron todo lo más d'Espanna; et cómo fueron los cristianos después cobrando la tierra; et del danno que uino en ella por partir los regnos, por que se non pudo cobrar tan aýna; et después cuémo las ayuntó Dios, et por quáles maneras et en quál tiempo 
La primera parte de la Crónica general, la Estoria de España, presenta la historia del mundo antiguo. Comienza partiendo de la Biblia, y en ella encuentra el origen de los españoles: "el quinto fijo de Japhet, que ouo nombre Thubal, donde uinieron los espannoles" (t. 1, p. 6); termina desembocando, y cerrando así el círculo, otra vez en la Biblia: el "destroymiento" de España recuerda el de Jerusalén, y la lamentación de Alfonso se puebla de resonancias de Jeremías ${ }^{\tilde{z}}$. La segunda parte, Corónica de España, que conserva el mismo ritmo bíblico, describe el lento progreso con que los cristianos ayudados por Dios recobran la tierra de sus padres. Comienza en don Pelayo, "primero rey de León" (t. 2, p. 321), y en el principio de la reconquista: "el qual [don Pelayo] cercaron los moros en la cueua de Onga, que es en Asturias de Oviedo"; termina, cerrando el círculo, en Fernando III, último rey de León, y en el fin de la reconquista: "Sseñor te dexo [dice don Fernando al futuro Alfonso $\mathrm{X}$ ] de toda la tierra de la mar acá que los moros del rey Rodrigo de Espanna ganado ouieron; et en tu sennorío finca toda, la vna conquerida, la otra tributada" (t. 2, p. 772).

De lo anterior se desprende que el método de trabajo del Rey Sabio trata de incluir el mayor número posible de elementos y materiales ${ }^{6}$; también que su concepto de España, geográfico por una parte e histórico por otra ${ }^{7}$, aunque comprendiendo siempre a todos los reinos peninsulares, se afina a veces hasta identificarse con el de Castilla y León. Por eso puede afirmar Alfonso que en su señorío queda toda la tierra que los moros ganaron a don Rodrigo, olvidando o silenciando a Navarra, Aragón y Portugal; y asegurar que Dios "ayuntó" la tierra de España refiriéndose a la unión de León y Castilla, y olvidando de nuevo los otros reinos peninsulares. Por último, queda patente también el deseo de Alfonso de captar y mostrar la continuidad histórica de Castilla. Para ello numera rigurosa-

et quáles reyes ganaron la tierra fasta en el Mar Mediterráneo; et qué obras fizo cada uno, assí cuémo uinieron unos empós otros fastal nuestro tiempo".

5 Es también reveladora la comparación de España con el "paraýso de Dios" -el terrenal, naturalmente-; y recuérdese que comienza la historia cuando el "omme por que passó mandamiento de Dios fue echado de paraýso" (ibid.. p. 4).

6 De acuerdo con el espíritu de la época, como María Rosa Lida de MaLKIEL ha señalado en su valioso artículo "La General estoria: notas literarias y filológicas" (I), RPh, $12\left(195^{8-59)}\right.$, p. 121 .

7 España es, incluso geográficamente, el perdido imperio de los godos: "España... es cerrada toda en derredor: dell un cabo de los montes Pireneos que llegan fasta la mar, de la otra parte del mar Occeano, de la otra del mar Tirreno. Demás es en esta Espanna la Gallia Góthica, que es la prouincia de Narbona dessouno con las cibdades Rodes, Albia y Beders que en tiempo de los godos pertenescien a esta misma prouincia. Otrossí en Áffrica auie una prouincia sennora de diez cibdades que fue llamada Tingitana, que era so el sennorío de los godos assí como todas estas otras" (Crónica general, ed. cit. t. 1, p. 311). 
mente a los reyes que "unos empós otros" se suceden desde don Pelayo hasta Fernando III. De ahf que al comenzar el reinado de cada monarca, aparezca siempre junto al nombre el número que le corresponde en esta serie:

Comiénçase el regnado del rey don Alffonsso el Magno que regnó en León, dozeno después del rey don Pelayo $(2,367)$; el regnado del primero don Sancho, que regnó en León diez et Ix después del rey don Pelayo, se comiença $(2,408)$; comiénçase el regnado del rey don Vermudo, que regnó xxı después del rey don Pelayo $(2,443)$; el regnado del rey don Fernando el Primero que regnó en Castiella et en León, $\mathrm{xx}$ et quarto después del rey don Pelayo, se comiença $(2,482)$; del regnado del tercero don Fernando, rey que regnó treynta et tercero después del rey don Pelayo en Castiella, et después a tiempo en León $(2,713)$.

El Rey Sabio convierte cada serie de reyes homónimos en una serie numerada cronológicamente ${ }^{8}$. Tres son los nombres que se repiten: Sancho, Fernando y Alfonso. En la serie astur-leonesa (7 111035) aparecen un Sancho (Sancho I el Gordo) y cinco Alfonsos (Alfonso I el Católico, Alfonso II el Casto, Alfonso III el Magno, Alfonso IV el Monje y Alfonso V el Noble); en la castellano-leonesa (1035-1157) un Fernando (Fernando I el Grande), un Sancho (Sancho II "el que murió sobre Zamora") y dos Alfonsos (Alfonso VI "el que conquistó Toledo" y Alfonso VII el Emperador); Alfonso VII parte los reinos, y desde entonces hasta Fernando III (1157-1217) encon-

8 Es difícil reconstruir la numeración alfonsi a causa de las muchas variantes que aparecen en los distintos manuscritos de la Crónica general. Con todo, creemos que hay suficiente base para imaginarla como la presentamos. El más antiguo de los códices manejados por Menéndez Pidal, el que denomina $E$ (finales del $\mathrm{xm}$ ), trae siempre la numeración que establecemos. Lo mismo sucede con el ms. $F$, más fiel a las fuentes que el ms. $E$. El manuscrito perdido utilizado por Ocampo coincide en la mayoría de los casos con la numeración que proponemos. Los otros, de los siglos xiv, Xv y xvi, reforman la numeración.-En los Fernandos y en los Sanchos, todos los códices están de acuerdo. Están de acuerdo también en los dos primeros Alfonsos. Se separan a partir de Alfonso III. En los mss. más modernos la serie aparece como sigue: Alfonso III, el Magno; Alfonso IV, el Ciego; Alfonso V, el Noble; Alfonso VI, el que ganó Toledo; Alfonso VII, el Emperador; Alfonso VIII, el de las Navas; Alfonso IX de León. El códice utilizado por Ocampo, el $F$ y el $E$, y a veces algunos otros, la presentan así: Alfonso I, el Católico; Alfonso II, el Casto; Alfonso IV, el Magno; Alfonso V, el Ciego; Alfonso VI, el Noble; Alfonso VII, el que ganó Toledo; Alfonso VIII, el Emperador; Alfonso IX de Castilla, el de las Navas; Alfonso IX de León. En la última serie falta un Alfonso, que debiera ser el tercero, pero puesto que entre Alfonso el Casto y Alfonso el Magno ni hubo ni se podía intercalar otro Alfonso, y puesto que entre Alfonso el que ganó Toledo y el Emperador reinó Alfonso el Batallador, creemos que es a éste al que se debe el cambio de la serie y que a él, como sucedió más tarde, se le asignó el número siete. 
tramos dos series distintas, la una en León con un Fernando (Fernando II) y un Alfonso (Alfonso IX), y la otra en Castilla con un Sancho (Sancho III el Deseado) y un Alfonso (Alfonso VIII el de las Navas). En 1217 se reúnen, en Fernando III, definitivamente los dos reinos.

La numeración del Rey Sabio, como su método de trabajo y su proceder doctrinal, no trata de valorar ni de seleccionar, sino de incluir. Cada uno de sus antecesores es un eslabón en la ininterrumpida cadena que une a Castilla con el imperio visigótico. $\mathrm{Y}$ así como Castilla es la heredera de todos los reinos que la precedieron (León y Asturias), Fernando III, el último rey de la crónica, es el descendiente de todos los reyes anteriores (castellanos, leoneses y asturianos). De ahí que en cada serie de reyes homónimos la numeración comprenda por igual a todos los monarcas (asturianos, leoneses, castellanos y castellano-leoneses). La innovación diferenciadora es, pues, un elemento más de que se vale Alfonso para acentuar la antigüedad y la continuidad de Castilla. Sirve también para hacer resaltar el espíritu integrador del reino castellano y a la vez subraya la importancia de Castilla, su predominio entre los restantes reinos peninsulares. Por eso el Rey Sabio no duda en acoger en la serie de los Alfonsos castellanos al aragonés Alfonso el Batallador, que por su matrimonio con doña Urraca reinó en Castilla y León, y que gracias a León y a Castilla pudo denominarse emperador de España.

La numeración ${ }^{9}$ de la Crónica de España queda como sigue:

Numeración actual

Alfonso I
Alfonso II
Alfonso III
Alfonso IV
Alfonso V
Alfonso VI
(Alfonso el Batallador)
Alfonso VII
Alfonso VIII
Alfonso IX
Sancho I
Sancho II
Sancho III

Numeración de Alfonso

Alfonso I
Alfonso II
Alfonso III
Alfonso IV
Alfonso V
Alfonso VI
Alfonso VII
Alfonso VIII
Alfonso IX de Castilla
Alfonso IX de León
Sancho I
Sancho II
Sancho III

Alfonso I

Alfonso II

Alfonso III

Alfonso VII

Alfonso VIII

Alfonso IX de Castilla

Alfonso IX de León

Sancho II

${ }^{9}$ Primera crónica general, ed. cit., t. 2, p. 643: "El capftulo de cómo este rey don Alffonso el Sesto [E I F "seteno"] ... se ueno pora Toledo con su hueste"; p. 649: "Del regnado dell seteno [E $F$ "octavo"] don Alffonso... que fue después emperador de Espanna"; p. 676: "Del regnado del noueno don Alffonsso rey de León, nieto dell Emperador"; p. 678: "El capítulo de las estrannas noblezas del ochauo [E F I "noveno"] don Alffonsso rey de Castiella et de la conquista de Cuenca". 
Fernando I

Fernando II

Fernando III
Fernando I

Fernando II

Fernando III

Esta numeración es la que predomina a lo largo del siglo xiv. Aparece en la Crónica abreviada del infante don Juan Manuel: "Este rey don Alfonso el ochauo [dice de Alfonso VII] ganó la cibdad de Coria" (ed. cit., 165); en la Crónica del rey don Alfonso Décimo: "Éste [el Sabio] fue el deceno rey de Castilla e de León, que por este nombre fue llamado" (ed. cit., 3); y en la Crónica de Alfonso XI: "Éste fue el onceno rey don Alfonso [Alfonso $\mathrm{XI}$ ] que así ovo nombre" 10 .

\section{Segunda numeración}

A finales del siglo xIv y durante buena parte del $\mathrm{xv}$, la numeración alfonsí es suplantada por otras de diferente carácter y estructura. Las nuevas maneras de numerar a los reyes castellanos, aunque distintas entre sí, tienen en común el punto de partida. No se trata de abarcar, sino de limitar. No interesa tanto ahora mostrar una Castilla que resuma todos los reinos anteriores y que represente en última instancia la totalidad hispana, como definir su realidad histórica ${ }^{11}$ y encontrar las características que revelen su individualidad. De ahí que la intención de los escritores del xv se encamine a presentar una España plural. Es cierto que su unidad está siempre sobreentendida, pero es una unidad de origen y destino. Es en el linaje (el godo) y en la ocupación (la reconquista) en donde coinciden los reinos españoles, y esto es lo que los diferencia de los otros pueblos cristianos. Pero la pluralidad de España se siente como una constante histórica, no como una situación temporal o fortuita. Se ve a Castilla como uno más entre los cuatro reinos peninsulares.

En el Xv se habla a menudo del parentesco hispánico, de la necesidad común de terminar la reconquista, pero hasta el matrimonio de Isabel y Fernando no aparece el deseo de reunir "los pedazos de España"; y aun entonces ni siempre es claro ni participan en él todos los teorizadores de nuevas formas políticas ${ }^{12}$.

10 Corónica del muy alto et muy católico rey don Alfonso el Onceno, Madrid, 1953, p. 391.

11 Américo Castro ha señalado ya la necesidad que siente Castilla a comienzos del xv de definir y publicar su personalidad: "No creo que ningún otro pueblo de Europa haya revelado a comienzos del siglo xv una tan redonda y cabal conciencia de sí mismo. Castilla sintió la ineludible necesidad de salir al mundo" (La realidad histórica de España, México, 1954, p. 24).

12 "Platicóse ansimesmo en el Consejo del rey e de la reyna [Isabel y Fernando] cómo se debían intitular; e como quiera que algunos de su consejo eran en voto que se intitulasen reyes de España, pues sucediendo en aquellos reynos e sennoríos de Aragón, eran señores de toda la mayor parte della, pero determinaron de lo no facer, e intituláronse en todas sus cartas en esta ma- 
El canciller Pero López de Ayala introduce en la Crónica del rey don Pedro ${ }^{13}$ una nueva numeración, la cual, respondiendo al deseo de presentar sin confusión el discurrir histórico de Castilla, excluye a los reyes que entre 1157 y 1217 reinaron en León; excluye también, rechazando intervenciones extrañas, al aragonés Alfonso el Batallador. De esta manera la cadena de reyes castellanos se remonta, sin la interrupción leonesa, desde Enrique III, en cuyo tiempo se escribe la crónica, a través del reino astur-leonés y del imperio godo, hasta Atanarico, "el primero rey godo que vino en España".

La serie de reyes de nombre Alfonso queda en la Crónica del rey don Pedro como aparece a continuación:

Numeración actual
Alfonso I
Alfonso II
Alfonso III
Alfonso IV
Alfonso V
Alfonso VI
Alfonso VII
Alfonso VIII
Alfonso IX
Alfonso X
Alfonso XI

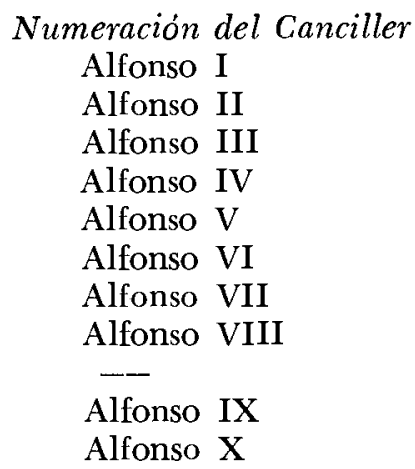

Es cierto que de todos los Alfonsos con los que construímos la serie, el Canciller sólo cita a Alfonso $\mathrm{X}^{14}$ (el XI en la numeración actual). Lo único que sabemos con certeza, por lo tanto, es que $\mathrm{Al}$ fonso XI ocupa, según López de Ayala, el décimo lugar entre los Alfonsos de Castilla. Para llegar a este resultado bastaba suprimir de la serie alfonsí a Alfonso el Batallador ${ }^{15}$. De todos modos creemos acertar al excluir también de la serie a los dos reyes de León (Fernando II y Alfonso IX).

Afirma en el proemio López de Ayala: "Debedes saber que del primero rey godo que vino en España que fue christiano, que fue llamado Atanarico, fasta el rey don Rodrigo, que fue el postrimero rey de los godos, ovo treinta e cinco reyes. E dempués que la tierra

nera: Don Fernando e Doña Isabel, por la gracia de Dios, Rey e Reyna de Castilla, de León, de Aragón, de Sicilia, de Toledo, de Valencia..." (Crónica de los muy altos y esclarecidos don Fernando e doña Isabel, ed. cit., p. 342).

13 Edición de Cayetano Rosell, Madrid, 1953.

${ }_{14}$ El editor corrige la numeración de López de Ayala, y escribe Alfonso XI. En la edición de 1779, Eugenio de Llaguno advierte la diferencia, y respeta la numeración del Canciller.

15 Hubiera quedado así: Alfonso VI, el que ganó Toledo; Alfonso VII, el Emperador; Alfonso VIII de Castilla (el de las Navas); Alfonso IX, el Sabio; Alfonso X, el del Salado. 
de España fue conquistada por los moros, quando Tarif e Muza pasaron con consejo del conde don Illán, fincó rey en las Asturias el rey don Pelayo, fijo del conde don Pedro de Cantabria, que venía de aquel linage de los godos. $\mathrm{E}$ ovo dél reyes fasta el rey don Alfonso, que venció la batalla de Tarifa a Abulhacén, rey de Fez e de Marruecos e de Sujulmeza e de Túnez, treinta e cinco reyes". Comenta Rosell: "Más cierto es el número de los reyes godos que se pone en este Proemio desde el rey Atanarico hasta el rey Rodrigo, que el que se señala de los reyes desde don Pelayo hasta don Alfonso, padre del rey don Pedro, que se dice ser también treinta y cinco reyes, porque se hallan más; y así creo que está errada esta letra por culpa de los escribientes y no del autor" (p. 40o, nota 1). Para nosotros en esa letra errada por culpa de los escribientes está la clave de la numeración del Canciller. Es verdad que según la serie alfonsí hay que contar treinta y siete reyes desde don Pelayo hasta Alfonso XI, pero si se excluye a los dos reyes de León (Fernando II y Alfonso IX), como creemos que hace López de Ayala, quedan exactamente los treinta y cinco que cuenta el proemio ${ }^{16}$.

Fernán Perez de Guzmán utiliza el mismo sistema en los Loores de los claros varones de España. La intención de la obra se expone en los primeros versos (ed. cit., p. 707a): cantar y publicar a los sabios y a los príncipes españoles, como el Eclesiastés había hecho con los hebreos ("Loemos los muy famosos / príncipes de nuestra España, / según que Cirac se baña / en loar los gloriosos / varones e virtuosos / príncipes del pueblo ebreo"). Pérez de Guzmán entiende por España no sólo Castilla, sino los cuatro reinos peninsulares, y cuida bien de indicarlo: "Todos los reyes de España / que Alfonsos fueron llamados / (ved gracia de Dios estraña) / que todos fueron dotados / de virtudes... / Non digo singularmente / que en Castilla e León / fue este nombre excelente, / mas Portugal e Aragón, / reynos de aquesta nación" (p. 720b). Pero el discurrir histórico del reino castellano, aunque parejo al de las otras partes de España, se traza con toda nitidez. El nacimiento de Castilla, reacción frente a León, se debe al deseo de libertad de los castellanos, y su proceso histórico, desde el comienzo, se desarrolla en pugna con los reinos vecinos (moros y cristianos) ${ }^{17}$; de ahí la necesidad de estable-

16 Compárese la descripción que de Alfonso XI hace el Canciller con la de la Crónica de Alfonso el Onceno, la cual sin duda le sirvió de modelo. Dice la crónica: "Fue el rey don Alfonso non muy grande de cuerpo, mas de buen talente, et de buena fuerza, et rubio et blanco, et venturoso en guerras. Et éste fue el onceno rey don Alfonso que así ovo nombre" (ed. cit., p. 391); y el Canciller: "Fue este rey don Alfonso non muy grande de cuerpo, mas de buen talle e de buena fuerza, e blanco e rubio e franco e esforzado e venturoso en guerras: e éste fue el deceno rey don Alfonso que así ovo nombre" (p. 404).

${ }_{17}$ Ibid., p. 725a: “Éste [Fernán González] libertó a Castilla / de la cruel 
cer la línea sucesoria de sus monarcas exenta de presencias extrañas y $\sin$ deudas a numeraciones ajenas ${ }^{18}$. De acuerdo con esta serie numeran a Alfonso el Sabio algunas ediciones de las Partidas (Las siete partidas del sabio rey Alfonso el IX). Los editores, que no tienen en cuenta los precedentes medievales, lo explican a su manera ${ }^{19}$.

\section{Tercera numeración}

Cuando, en agosto de 1434, llegan los embajadores del rey de Castilla al Concilio de Basilea, se plantea una cuestión de protocolo. $¿ Q u i e ́ n e s$ han de preceder en las ceremonias del Concilio: los ingleses o los españoles? Alfonso de Cartagena, obispo de Burgos, representante de Castilla, se encarga de mostrar el derecho que ostentan los castellanos. El 2 de septiembre pronuncia el famoso discurso Sobre la precedencia del Rey Católico sobre el Rey de Inglaterra ${ }^{20}$. Apoyándose en la Biblia, Aristóteles, Bartolo de Sassoferrato, Vicente de Beauvais y en las costumbres de la Iglesia, Cartagena llega a la "conclusión" de sus "conclusiones": "Los muy poderosos reyes de Castilla e de Inglaterra muy dignos son de muy gran honor, pero el muy Cathólico rey de Castilla deve ser con mayor abundancia de

seruidumbre, / que es muy amarga costumbre, / e lo que es más marauilla / que con pequeña quadrilla, / pero con pesada mano, / del muy gran pueblo pagano / triunfó en alta silla. // A nauarros e a moros / en muchas lides venció, / e de sus grandes thesoros / a Castilla enriqueció. / Conquistó e reparó / tantas villas e cibdades, / porque en todas las edades / su nombre resplandesció".

18 Loores de los claros varones de España, ed. cit., pp. $7^{21 b-722 a: ~ " F u e ~}$ quarto en el principado / e segundo en el nombre / déste, el qual por renombre / fue el Casto Alfonso llamado"; p $723 b$ : "Don Alfonso el tercero, / que por actos de gran fama / el Magno o Grande se llama"; p. 736b: "Por que en la fe subcedió [Fernando el Santo] / a don Alfonso el Primero; / fue legítimo heredero / del Rey Casto; por que amó / castidad e la guardó. / Fue magno como el tercero; / del sesto fue compañero / por que tanto conquistó"; p. 743a: "Éste fue el rey noueno [Alfonso el Sabio] / de aquella noble compaña / de los Alfonsos de España, / entre los muy buenos, bueno"; p. $746 b$ : "Fue [Alfonso XI] del glorioso nombre / de los Alfonsos dezeno, / tanto fuerte, tanto hombre / como el mejor, e tan bueno".

${ }^{19}$ Edición y traducción de Ignacio Sanponts y Barba, Ramón Martí de Eixada y José Ferrer y Subirana, Barcelona, 1843. Explican los editores (t. 1, p. 5, nota 1): "Se le pone en esta edición el nono o noveno, por seguirse en ella el texto de Gregorio López, dando por omitido de la serie de los reyes de Cas. tilla el Don Alonso, que lo era sólo de León, marido de doña Berenguela, por haber ésta renunciado, luego de suceder a su hermano don Enrique, la corona de Castilla, a favor del hijo de la misma, San Fernando. Sin esta omisión don Alonso el Sabio es el décimo, según se le designa de este modo ahora comúnmente; así como sería el undécimo si se contase además en la serie a don Alonso llamado de Aragón, que generalmente se deja por considerarse nulo su enlace con la reina doña Urraca, a la cual de otra parte sucedió un hijo de su primer matrimonio".

${ }^{20}$ En Prosistas castellanos del siglo $x \mathrm{v}$, ed. cit., p. 205. 
honor por la universal Eglesia tractado" (p. 224). A través de su discurso, que contiene todos los tópicos que sobre la monarquía y la nobleza repiten los tratadistas del $\mathrm{xv}$, y entremezclándose con sus fórmulas silogísticas, con sus pruebas y sus refutaciones, aparece claro su concepto de España y de Castilla. Los reinos españoles, unidos por el linaje y por la guerra divinal, constituyen esa unidad a la que llama España. España, múltiple y variada, a la que no hay inconveniente en denominar Españas, se dibuja desde el principio de su historia como una pluralidad. Gracias a eso Castilla es incomparablemente más antigua que Inglaterra; porque no nace ni con Fernán González ni con Fernando el Magno, sino que su origen se pierde en lo más remoto de la antigüedad: "En España, e aun en aquella parte de España que se llama Castilla, ovo reyes antes de la primera destrucción de Troya. Ca Hércoles... vino en España e ovo batalla en canpo con Gerión, rey de España. E aun más specialmente hablando, aquel Gerión era rey de Castilla... E así, de Gerión, rey de España, o más propiamente fablando rey de Castilla, fasta el día de oy, son pasados dos mill e seiscientos e tres años e aun más. E non dubdo que ante de aquel Gerión ovo otros reyes, aunque non sabemos sus nonbres por la grande antigüedad. E así el regno de Castilla es de los más antiguos regnos del mundo" (p. 212).

Castilla, el más importante de los reinos hispanos ("Los reyes de España, entre los quales el principal e primero e mayor es el rey de Castilla e de León", p. 210), está a su vez constituida por diversas naciones: "Ca so el señorío de mi señor el rey hay diversas nasciones e diversos lenguajes del todo" (p. 219), con lo que se llena el requisito que Salomón y Aristóteles exigen a la grandeza de la nación: "La muchedunbre del pueblo es la dignidad del rey", dice Salomón; y según Aristóteles, lo es "muchedunbre de tierra, posesión de villas diversas entre sí en muchedunbre e grandeza e fermosura" (p. 218).

Después de exponer su concepto de España pasa a explicar la función de Castilla: velar por el parentesco nacional, ilustrar y dar reyes a las diversas partes de España, ocuparse en "guerra divinal": "Mi señor el rey de Castilla, considerada la sangre de sus antecesores, es muy noble: ca no solamente desciende de los reyes de los godos e de las casas de Castilla e de León, mas aun de linage de todos los reyes de España: ante, más propiamente fablando, todos los reyes de España descienden de su casa" (p. 208) ${ }^{21}$; por otra par-

21 Incluso al hablar de épocas anteriores a la venida de los árabes se siente a España como una dualidad y se piensa en una guerra que podría ser "divinal": "Por Sant Gregorio me inclino / a loar el grant Trajano, / el rey que con fuerte mano, / e con deuota porfía / conquistó el Andaluzía / vençiendo al pueblo pagano". Hace tiempo que Américo Castro advirtió esta característica. 
te, "manifiesta cosa es que mi señor el rey de Castilla continuamente faze guerra contra los paganos e infieles, e por consiguiente es ocupado de fecho en guerra divinal por mandado del soberano enperador que es Dios" (p. 221 ).

Los ordinales con que el obispo de Burgos distingue a los reyes homónimos destacan los presupuestos de donde parte. La numeración incluye a los monarcas de todos los reinos que han producido esa variedad castellana: Asturias, León y Castilla. Pero a su vez rechaza a los que, al introducirse en la línea sucesoria castellano-leonesa, podían significar que la función de Castilla había quedado sin vigencia en una determinada época. Así no es de extrañar que se excluya a Alfonso el Batallador; no es Aragón el que dio monarcas a Castilla, sino Castilla a Aragón, y no hay que acudir, para probarlo, a testimonios lejanos; ahí está, treinta años antes, don Fernando de Antequera, que introduce en Aragón la dinastía castellana.

La numeración de Alfonso de Cartagena coincide con la actual ${ }^{22}$.

\section{Cuarta numeración}

Juan de Mena en su Laberinto ${ }^{23}$, coplas 271-291, canta la gloria de Juan II:

Será rey de reyes, señor de señores, sobrando e venciendo los títulos todos, e las fazañas de los reyes godos, e rica memoria de los sus mayores; e tal e tan alto favor de loores sus fechos ilustres a tu rey darán, que en su claro tienpo del todo serán con él olvidados sus antecessores.

El poeta, para glorificar al rey de Castilla, enumera las hazañas de los reyes que le antecedieron. Un verbo en futuro, antes o después del nombre del monarca que se recuerda, indica que la fama, sea cual sea, de éste, ha de ser superada por la de los hechos próximos de don Juan II. Mena utiliza veintiuna coplas. La primera es un anuncio y un resumen de las restantes: "Será rey de reyes,... con él olvidados sus antecesores". En las veinte siguientes se enumera a los monarcas elegidos. La enumeración nos lleva desde la mitología, a través de la historia, y mediante un riguroso orden cronológico, hasta el presente. Desde Gerión (primer verso de la copla 272) hasta Juan II (último verso de la serie). La enumeración trans-

22 Ed. cit., p. 208: "Don Fernando, primogénito de don Alfonso el dezeno que ovo este nonbre, rey de Castilla, casó con fija de aquel rey don Luis de Francia que fue canonizado por el Papa Bonifacio Octavo"; p. 211: "Ca don Alfonso, el seteno que ovo este nonbre, se llamó enperador de las Españas".

23 Edición de José Manuel Blecua, Madrid, $195^{1}$. 
curre dentro de un cauce temporal, pero sin límites temporales. Si su comienzo, fuera del tiempo, confiere a la antigüedad de España una vida y una grandeza fabulosas, su término, ahora en el tiempo, en el presente, le promete una duración y una grandeza heroicas.

En estas veinte coplas reparte Mena los veintinueve reyes que le interesa recordar. La elección no se apoya siempre en una valoración. Reyes buenos y malos, proezas y hechos insignificantes, reinados notables e intranscendentes, aparecen en esta galería de memorias hispanas. El porqué de la elección se desprende de las palabras que pronuncia la Providencia en la copla primera de su profecía. Si los hechos de don Juan han de hacer olvidar los de sus antecesores, la enumeración comprenderá a sus antecesores precisamente. Al trazar la línea de los antepasados de Juan II, Mena está dibujando el discurrir histórico de Castilla. Castilla, uno de los reinos de España, pero ahora más que nunca el mayor y el portavoz de todos ellos, se ajusta exactamente a la descripción histórico-extratemporal que establece la Providencia. Castilla desde Gerión, engrandeciéndose con los visigodos, apoyándose en Asturias, e irrumpiendo triunfal con los jueces y primeros monarcas castellanos, llega al momento de Juan II, y se prepara a su heroico destino. Así pueden distinguirse tres etapas en la enumeración. La primera se refiere a los reyes visigóticos, coplas 272 y 273 ; la segunda a los reyes de Asturias, 274-278; y la tercera a los reyes de Castilla, 279-291. Se excluye el período leonés $\left(1157^{-1217}\right)$ y el astur-leonés (711-1035). En dos coplas habla de la primera etapa, en cinco de la segunda y en trece de la tercera. El modo de tratar cada momento no se diferencia sólo en el número de coplas empleadas, sino también en el número de monarcas presentados. Así, mientras en los dos primeros se nombran únicamente algunos reyes, y aquí es posible la valoración, en el tercero se nombra rigurosamente a todos.

Por esto los ordinales que Mena utiliza no coinciden con los de las numeraciones anteriores ${ }^{24}$. La serie de Mena, que sólo incluye a los monarcas de Asturias y Castilla, queda como sigue ${ }^{25}$ :

24 Hernán Núñez, en su Copilación de todas las obras del famosissimo poeta Juan de Mena, Toledo, 1548, fol. xciiia, advierte la variación y la explica a su manera: "La razón no está en prompto a todos, y es ésta: que como en las historias de España se lea auer reynado en ella hasta nuestros tiempos onze llamados por este nombre [Alfonso], de todos estos onze haze tan solamente en esta obra mención de siete dellos, que fueron los más illustres y que más principales cosas hizieron. Y según va diziendo de cada uno destos siete, assí va nombrando al uno primero, e al siguiente segundo, e al tercero, e assi de todos". El Brocense, en Las obras del famoso poeta Juan de Mena, Salamanca, $15^{82}$, p. $9^{2}$, explica la variación de la misma manera. MARía RosA Lida de Malkiel, Juan de Mena, poeta del Prerrenacimiento español, México, $195^{\circ}$, p. 45 , acepta la explicación del Comendador Griego.

25 El laberinto de Fortuna, ed. cit., pp. 140-146 (coplas 275-288): "e los claros fechos de Alfonso el Primero, / aquel que a Segovia ganó de guerrero"; 
Numeración actual

\section{Alfonso I \\ Alfonso II \\ Alfonso III \\ Alfonso IV \\ Alfonso $\mathrm{V}$ \\ Alfonso VI \\ Alfonso VII \\ Alfonso VIlI \\ Alfonso IX \\ Alfonso $\mathrm{X}$ \\ Alfonso XI}

Sancho I

Sancho II

Sancho III

Sancho IV

Fernando I

Fernando II

Fernando III

Fernando IV
Numeración del "Laberinto"

Alfonso I

Alfonso II

Alfonso III

Alfonso IV

Alfonso $\mathrm{V}$

Alfonso VI

Alfonso VII

Sancho I

Sancho II

Sancho III

Fernando I

Fernando II

Fernando III

Coincidiendo con la numeración de Mena, la Crónica de veinte reyes llama a Sancho el Deseado (el tercero en la serie actual) Sancho II. Nosotros, en desacuerdo con Theodore Babbitt, nos inclinamos a creer que la variación obedece a la misma actitud histórica ${ }^{26}$.

\section{Reaparece la primera numeración}

La subida de un aragonés al trono de Castilla es previsible y casi evidente después del matrimonio de Isabel y Fernando. Así lo sienten los escritores castellanos de finales del xv, y se apresuran a buscar razones para presentar el hecho de manera que ni la gloria ni la función rectora de Castilla disminuyan. La situación queda inmediatamente explicada. El príncipe aragonés sube al trono de los Alfonsos, Sanchos y Fernandos por ser su descendiente, por venir de su linaje, por ser, en última instancia, castellano. Entra y se sitúa

"Callarse han los fechos del Magno Fernando, / de Sancho su fijo, e Alfonso el terçero, / que el fuerte Toledo ganó de primero"; "El quarto Alfonso que fue enperador"; "Del quinto Alfonso... / que la de las Navas venció de Tolosa"; "ternedes en poco los fechos del sesto / Alfonso, persona de tanto misterio, / que fue de Alemaña llamado al inperio"; "Veredes a Sancho terçero callando, / aquel que la fuerte Tarifa conquiso"; "del terçer Fernando, / aquel que Alcaudete ganó batallando, / del que se dize morir enplazado"; "El sétimo Alfonso... / ...que puso por suelo / a todos los reyes de Benamerín".

${ }^{26}$ La crónica de veinte reyes, ed. Theodore Babbitt, New Haven, Conn., 1936, p. 129, nota 1. 
en la serie de los monarcas de León y Castilla por su propio derecho ${ }^{27}$. Así se dirige frey Iñigo de Mendoza a doña Isabel y don Fernando:

\author{
$\mathrm{Y}$ que vosotros sobréys \\ en mayores crecimientos, \\ alos reynos lo deuéys, \\ por que entramos procedéys \\ de tan reales cimientos; \\ soys de cepa natural \\ castellanos como muestro, \\ y lo que ay de Portogal \\ no nos puede hazer mal \\ para demandar lo vuestro...
}

Rey muy alto y escogido,

en ventura sobre todos,

vos, señor esclarescido,

soys onzeno ${ }^{28}$ rey venido

del linaje de los godos,

do vuestro nonbre es hallado

en grandeza syn medida,

de quien es prophetizado

cosas altas syn peccado

dándovos Dios, señor, la vida ${ }^{29}$.

De la misma manera se precisa el carácter de la intervención aragonesa. El nuevo príncipe es el encargado de redimir la deuda

27 "Hablóse ansimesmo allí en Segovia acerca de la subcesión del reyno. Porque algunos de los grandes que eran parientes del rey decian que pues el rey don Enrique falleció sin dexar generación, estos reynos pertenecían de derecho al rey don Juan de Aragón padre del rey, porque no había otro heredero varón legítimo que debiese subceder en los reynos de Castilla, salvo él, que era fijo del rey don Fernando de Aragón e nieto del rey don Juan de Castilla; e por consiguiente venía de derecho al rey don Fernando su fijo, marido de esta reyna doña Isabel" (Crónica de los muy altos y esclarecidos don Fernando y doña Isabel, ed. cit., p. 255).

${ }^{28}$ El onceno rey a partir de Alfonso el Sabio. Quizá por influjo de los cronistas que solian elevar la genealogía de los reyes historiados precisamente hasta el rey Sabio. Así en la Crónica del rey don Sancho el Bravo, ed. cit., p. 69: "Aquí comienza la crónica del rey don Sancho el Bravo, fijo del rey don Alfonso Décimo". En la Crónica del rey don Fernando IV, ed. cit., p. 93: "Aquí comienza el reinado del rey don Fernando, fijo del rey don Sancho e nieto del dicho señor rey don Alfonso emperador". Y en la Crónica del rey don Juan el Segundo, ed. cit., p. 277: "Este preclarísimo rey don Juan, segundo deste nombre, fue hijo del christianísimo príncipe don Enrique III y de la muy esclarecida princesa doña Catalina... e fue nieto del rey don Juan Primero e de la reyna doña Leonor, hija del rey don Martín de Aragón, e fue viznieto del muy excelente rey don Alonso Onceno, que venció la gran batalla de $\mathrm{Be}$ lamerin..., e fue descendiente en seteno grado... del rey don Alonso Deceno, que fue elegido por emperador".

${ }_{29}$ Cancionero castellano del siglo $x y$, ed. cit., t. 1, pp. $66 b$ y $67 a$. 
que Aragón había contraído con Castilla desde el tiempo de Fernando de Antequera. Si un rey castellano dio Castilla a Aragón, un rey castellano devuelve Aragón a Castilla. Al mismo tiempo se considera a don Fernando el rey elegido por el cielo para dar cumplimiento a las profecías que no se habían realizado en los monarcas anteriores $^{30}$. Al cabo, la vieja promesa de Merlín, la anhelada terminación de la conquista, iba a efectuarse:

Verná de leuante un çirio ençendido que alunbrará la montaña escura, por su lealtança sserá por mesura delos esperantes muy bien resçebido... De allí partirá su pendón tendido, el bien costelado con buena ventura; el pueblo agareno de mala natura será conquistado e todo estroydo ${ }^{31}$.

$\mathrm{Y}$ por el matrimonio de Isabel y Fernando, y por la gracia del cielo, las partes de España, desde el tiempo de don Rodrigo apartadas y esparcidas, iban a recobrar su unidad primera: "Muy humano señor..., de quien es profetizado de muchos siglos acá que no solamente seréis señor de estos reinados de Castilla e Aragón, que por todo derecho vos pertenescen, mas avréis la monarchía de todas las Españas e reformaréis la silla imperial de la ínclita sangre de los godos donde venís, que de tantos tiempos acá está esparzida e derramada..." 32

De ahí que sin vacilación alguna se numere a don Fernando según los ordinales castellanos:

Príncipe de cuyo nombre quatro reyes son passados, justiçieros, esforçados, dignos de muy gran renombre, mis rodillas por el suelo ante vuestra Majestad, mal trobando como suelo, quiero fablar sin recelo y deziros la verdad ${ }^{33}$.

A finales del Xv reaparece la numeración alfonsí. El método del Rey Sabio, que acepta en la serie castellana a un rey aragonés (el

30 Américo Castro, en La realidad histórica de España, op. cit., p. 29, ve así la venida de los Reyes Católicos: "Esta voluntad anhelante de un jefe que mande y guíe dará al advenimiento de los Reyes Católicos un aire de profecía que se cumple, de Mesías que al fin llega".

$3 \pm$ Alfonso Álvarez de Villasandino en el Cancionero castellano del siglo $x v$, t. 2, p. $4 \mathrm{I} 6 a b$.

32 Diego de Valera, Doctrinal de principes, ed. cit., p. 173.

33 Gómez Manrique en el Cancionero castellano del siglo xv, t. 2, p. $113 b$. 
Batallador), se acomoda a la nueva situación de Castilla. También el sistema de Alfonso, que, incluyendo en la serie el mayor número posible de reyes hispanos, conduce a la unidad de León y Castilla, llena las exigencias de un momento en que se ve a Isabel como una segunda Berenguela forjadora de la unidad nacional: "Así como la muy ecelente reina doña Berengela ayuntó estos reinos departidos, de Castilla e de León, e con su gran discrición y prudencia domó la sobervia desta vuestra mayor España, así vos, Señora, los avéis ayuntado con Aragón y Secilia, e avéis acabado tan grandes cosas con el ayuda de Dios e del viguroso braço de nuestro Serenísimo Rey e Señor"34.

El más característico representante del segundo momento de la numeración alfonsí es Mosén Diego de Valera ${ }^{35}$. La utiliza también el Comendador Griego en sus anotaciones al Laberinto $^{36}$. Camões ${ }^{37}$ la lleva hasta los umbrales del $\mathrm{xvn}^{38}$.

\section{Quinta numeración}

Esteban de Garibay y Gonzalo Argote de Molina, en los últimos decenios del xvi, mantienen la vigencia de la numeración alfonsí. Pero ahora no se llega a ella a través de una tradición histórica,

34 Diego de Valera, Epistolas, en Prosistas castellanos del siglo xy, ed. cit., p. 17 .

35 "De la begninidat [sic] e franqueza del rey don Alfonso el Cathólico, que fue primero deste nombre en esta vuestra España" (Doctrinal de principes, ed. cit., p. 176); "Del rey don Alfonso el Casto, que fue segundo deste nonbre en estos reinos" (ibid., p. 185); "Se lee del rey don Alfonso el Magno, que fue tercero deste nonbre, que se dio mucho a la ciencia" (p. 182); "De Alimaimón rey de Toledo se lee que, como el rey don Alfonso, sesto deste nonbre, estoviese en Toledo..." (p. 191); "De don Alfonso emperador d'España, que fue octavo deste nonbre..." (p. 176); "El rey don Alonso, noveno deste nonbre, que perdió la batalla de Alarcos e ganó la de las Navas de Tolosa" (Epistolas, p. 23); "Don Alfonso, dezeno deste nonbre, que fue elegido por enperador" (Doctrinal, p. 182); "El rey don Alfonso, honzeno deste nombre, que fue padre del rey don Pedro" (p. 177).

${ }^{36}$ Op. cit., fol. xciiib: "Después de la muerte del rey don Alonso el Emperador de España, octauo de este nombre". Al suprimir el Brocense de su serie al Batallador, lo confunde con Alfonso VIL Así presenta a Alfonso VII casado con doña Urraca, en realidad su madre, esposa del Batallador: "Succedióle [a Sancho II] Alonso su hermano, sexto deste nombre, que ganó a Toledo... Succedió a éste Alonso séptimo... llamado Emperador, casó con doña Urraca hija del pasado" (op. cit., p. 92).

37 Os Lusiadas, Lisboa, 1931, p. 264: “¿Não vês um Castelhano, que, agravado / de Afonso nono, Rei, pelo ódio antigo / dos de Lara, co'os Mouros e deitado, / de Portugal fazendo-se inimigo?"

38 Ésta debe ser también, probablemente, la serie de Alfonso de Palencia: "Vivió Alfonso XII [el infante don Alfonso, hermano de Isabel la Católica], rey de Castilla y León, catorce años, siete meses y veinte días" (Crónica de Enrique IV, traducción de Paz y Mélia, Madrid, 1904, t. 2, p. 154). 
sino mediante una reconstrucción lógica. De ahí que aunque incluyan a los mismos monarcas que incluía Alfonso, los ordinales varíen.

A fines del xvi los historiadores y los cronistas se preocupan de señalar las diferencias entre Aragón y Castilla, y tratan de defender la personalidad y las prerrogativas de su nación de origen $^{39}$. En cambio, la unidad de Castilla y León es ya un hecho reconocido y aceptado. Al reconstruir ahora la numeración alfonsí, lo importante es presentar la unidad de los dos reinos peninsulares como ya consumada. Para el Rey Sabio los reyes de León y los de Castilla, aunque dentro de una misma serie numérica, eran precisamente reyes de León o Castilla (por eso tras Alfonso VIII, el VII en la numeración actual, venían Alfonso IX de Castilla, VIII en la actual, y Alfonso IX de León, IX en la actual). En cambio, para los historiadores de finales del xvi los reyes de León y los de Castilla están dentro de la misma serie, porque León y Castilla forman una unidad (así, tras Alfonso VIII, VII actual, vienen Alfonso IX, VIII actual, y Alfonso X, IX actual): "Muerto el rey don Fernando", explica Argote de Molina, "luego el infante don Pedro alȩó el Pendón Real por el rey don Alfonso su sobrino, infante primogénito heredero de los reynos. La historia impresa de este rey le llama onzeno, y en conformidad de ella le e llamado yo siempre assí, por guardar el título de su chrónica, quando con ella alego. Mas entre los reyes de Castilla y de León es el último y el duodécimo, como notó muy bien Estevan de Garivay y Camalloa en el cap. I del lib. 14. El primero fue el rey don Alfonso el Católico. El segundo, el Casto. El tercero, el Magno. El quarto, el que murió ciego. El quinto, el que murió sobre Viseo. El sexto, el que ganó a Toledo. El séptimo, el marido de la reyna doña Urraca. El octavo, el emperador de las Españas. El noveno, el que venció la batalla de Úbeda. El décimo, padre del sancto rey don Fernando. El undécimo, el Sabio. El último, el presente rey"40.

39 Los cronistas e historiadores aragoneses de la época se preocupan mucho de construir la serie de sus monarcas libre de interferencias castellanas. Véanse los siguientes ejemplos tomados de La erudición española en el siglo xvii de Ricardo del Arco y Garay, Madrid, 1950. Del Memorial de don Jaime Ximénez de Ayerbe: "Y para que se conozca cuánta fue su diligencia, se copiará el memorial que dio al Señor Rey Don Felipe I en esta corona, y segundo en la de Castilla" (t. 1, p. 269); del Elogio de Juan Andrés, el Solitario, a su padre: "Mantua le vio con el caduceo de Mercurio, quando fue embaxador de Salduba a Felipo el Piadoso, II de Aragón i III de Castilla" (t. 1, p. 107).Tienen el mismo sentido algunas numeraciones construidas en el xIX. Cf. BENito VicetTo, Historia de Galicia, Ferrol, 1872, t. 6, p. 8: "La muerte de Enrique II de Galicia y III de Castilla, puso la corona en las sienes de su primogénito Juan II"; y p. 71: "Treinta años contaba Enrique III de Galicia y IV de Castilla cuando ciñó la corona por fallecimiento de su padre Juan II".

40 Nobleza del Andaluzia, Sevilla, 1588, p. 184 . Véase también el Discurso de la montería, Madrid, 1882, p. 3: "La Crónica suya que anda impresa le 
La numeración ${ }^{41}$ aparece como sigue:

Numeración actual
Alfonso I
Alfonso II
Alfonso III
Alfonso IV
Alfonso V
Alfonso VI
(Alfonso el Batallador)
Alfonso VII
Alfonso VIII
Alfonso IX
Alfonso X
Alfonso XI

Quinta numeración
Alfonso I
Alfonso II
Alfonso III
Alfonso IV
Alfonso V
Alfonso VI
Alfonso VII
Alfonso VIII
Alfonso IX
Alfonso X
Alfonso XI
Alfonso XII

Pero precisamente a finales del xvi recibe la numeración alfonsí los primeros ataques. Fray Prudencio de Sandoval aduce contra el sistema de Garibay razones que indican fielmente hasta dónde se desconocía la serie del Rey Sabio: Al Batallador, dice Sandoval, "Garibay quiere contarle en el número de los Alfonsos de Castilla y de León: importa poco, y creo que nos importa más quedarnos con la costumbre antigua, que Castilla nunca contó más de once reyes de este nombre que en ella y en León regnaron" 42 .

Casi dos siglos más tarde, el padre Flórez secunda con sus razonamientos la protesta de Sandoval. Razonamientos que, si tienen sentido en el xvir, pierden su validez al tratar de explicar la época de Alfonso"3: "Veiuntiún años tenía el rey don Alfonso cuando murió su madre doña Urraca... y aunque algunos le intitulan octavo, haciendo séptimo al aragonés por haber casado con la reina, no adoptamos el método ni admitimos en la serie de Castilla al de Aragón, no tanto por no haber sido legítimo el casamiento con doña Urraca cuanto por no haber tenido sucesión, pues los demás que entraron en número con los reyes de Castilla, todos fueron padres de reyes, como don Alfonso de León y don Fernando de Aragón y

llama onceno deste nombre; mas según la verdadera cuenta de los reyes de Castilla y de León, fue el duodécimo de los Alfonsos, porque el primero fue el Católico; el segundo, el Casto; el tercero, el Magno; el cuarto, el que murió ciego, hermano del rey D. Ramiro el Segundo; el quinto, el que murió sobre Viseo, padre del rey don Bermudo el Tercero; el sexto, el que ganó a Toledo; el séptimo, marido de la reina doña Urraca; el octavo, emperador de las Españas; el noveno, el que venció la batalla de Úbeda, en las Navas de Tolosa; el décimo, marido de la reina doña Berenguella, padre del rey don Fernando el Sancto; el undécimo, el Sabio; el duodécimo, el autor deste libro, último de los reyes deste nombre en Castilla y en León".

A1 Historia de los reyes de Castilla y León, Madrid, 1792, t. 2, p. 2.

42 De manera parecida explica la variación Eugenio Llaguno, Crónicas de los reyes de Castilla, Madrid, 1779 , t. 1, p. 1, nota 1.

${ }_{43}$ Memorias de las reinas católicas de España, Madrid, 1945, t. 1, p. 357. 
lo mismo don Felipe I. No habiendo, pues, dejado sucesión el marido de doña Urraca, ni tenido derecho al reino por sí mismo, no debe ser contado entre los reyes de Castilla".

\section{Sexta numeración}

El padre Flórez decide eliminar la confusión que las distintas numeraciones plantean. Le interesa, de acuerdo con el espíritu de la época, encontrar el método más claro y preciso. Para ello necesita especificar primero la entidad del reino castellano-leonés. Castilla y León, unas veces unidos y otras separados, constituyen, para el padre Flórez, esa entidad. Ahora la solución es fácil: dos ordinales deben acompañar el nombre de cada monarca, el primero para situarlo en la serie leonesa, el segundo en la castellana.

La numeración del padre Flórez se aparta por completo de las precedentes, de la misma manera que su punto de partida no tiene nada que ver con los anteriores. Hasta el xvirr los cronistas, desde diferentes actitudes, pretenden mostrar, apoyándose en los ordinales de los monarcas, la continuidad histórica de Castilla. El reino castellano, vinculado siempre a su origen, aparece con una función y un sentido. La numeración del padre Flórez, persiguiendo el nuevo propósito $^{44}$ (exactitud y claridad), presenta una Castilla separada de su origen y limitada a sus propias fronteras. Los ordinales ${ }^{45} \mathrm{cam}$ bian por completo y abruptamente ${ }^{46}$.

44 Propósito que no se cumple. Véanse las siguientes afirmaciones de la Clave historial, Madrid, 1749: "Alfonso IX de León sucedió en el reyno por muerte de su padre don Fernando" (p. 203); "Alfonso X, y de Castilla IV, llamado el Sabio" (p. 224); "Sancho IV, y III de Castilla, despojó a su padre del reyno" (p. 224).

46 Clave historial: "Alfonso VI y I de Castilla" (p. 182); "Alfonso VII y II de Castilla, h. Al título de rey añadió el antiguo de emperador" (p. 202); "Sancho, h. II de Castilla y III de León, pero no reynó en él por división que hizo su padre" (p. 203); "Alfonso VIII y III de Castilla de quatro años sucedió a su padre" (ibid.); "S. Fernando, III de León y II de Castilla, h. de la reyna Berenguela" (p. 223); "Alfonso X y de Castilla IV h. llamado el Sabio" (p. 224); "Sancho IV y III de Castilla despojó a su padre del reyno" (ibid.); "Fernando IV y III de Castilla" (ibid.); "Alfonso XI y V de Castilla, h. De edad de un año fue proclamado rey" (p. 243).

46 Probablemente existieron a lo largo de los siglos xIII, xIv y xv otras numeraciones en que nosotros no hemos reparado o que no hemos sabido interpretar.

El hecho de que la Primera crónica general presente por dos veces a Sancho el Bravo (IV en la numeración actual) como Sancho VII nos hace pensar en una posible serie que abarcara a todos los Sanchos de Navarra, León y Cas. tilla (Sancho Garcés I, Sancho Garcés II, Sancho Garcés III el Mayor, Sancho I de León, Sancho II el que murió sobre Zamora, Sancho III el Deseado, Sancho IV el Bravo). Don Ramón Menéndez Pidal, que cree en un error de los copistas ("Un tan descuidado y tan ignorante que leyó disparatadamente el numeral de la nota Sancho IIII creyendo que decía VII", y "un copista increíblemente ignorante, pudo leer Sancho VII"), apunta la posibilidad de otra ex- 
Numeración actual

Alfonso I
Alfonso II
Alfonso III
Alfonso IV
Alfonso V
Alfonso VI
Alfonso VII
Alfonso VIII
Alfonso IX
Alfonso X
Alfonso XI
Fernando I
Fernando II
Fernando III
Fernando IV
Sancho I
Sancho II
Sancho III
Sancho IV

Numeración del padre Flórez

\author{
Alfonso I \\ Alfonso II \\ Alfonso III \\ Alfonso IV \\ Alfonso $\mathrm{V}$ \\ Alfonso VI y I de Castilla \\ Alfonso VII y II de Castilla \\ Alfonso VIII y III de Castilla \\ Alfonso IX de León \\ Alfonso X y IV de Castilla \\ Alfonso XI y V de Castilla \\ Fernando I \\ Fernando II de León \\ Fernando III y II de Castilla \\ Fernando IV y III de Castilla \\ Sancho I \\ Sancho II y I de Castilla \\ Sancho III y II de Castilla \\ Sancho IV y III de Castilla
}

Seis diferentes maneras de numerar a los reyes de Castilla hemos estudiado en estas páginas. Todas son claros testimonios de actitu-

plicación: "La repetición del error en el numeral seteno es verdaderamente chocante. No quedo muy satisfecho de la explicación que doy, pero no se me ocurre otra". (Cf. Primera crón. general, p. xxxiii, nota I).

Agradecemos a don Rodolfo Ruibal una rarisima serie del xvirr. Aparece en la ejecutoria de filiación e hidalguía de su familia. La numeración de los Alfonsos se acomoda a la del Rey Sabio, pero cambian por completo los numerales que se asignan a los Sanchos: "Resplandeció por los años de mili ciento y veinte Sancho Bueno, capitán de cien lanzas y gran servidor del señor rey don Alonso el Sétimo el Batallador... Hernando Bueno, que sirvió de alférez al señor rey don Sancho el Quarto llamado el Deseado por los años de 1090 y prosiguió, hauiendo muerto este príncipe, sirviendo al señor rey don Alonso el Noveno cognominado el Bueno, hijo del dicho señor rey don Sancho" (Certificación de armas de la familia Bueno de las Herrerías, en Madrid, 1729).

Debe haber también explicaciones que den sentido a los distintos ordinales que acompañan el nombre de Isabel la Católica. Isabel Primera en casi todos los casos, pero Segunda para la Crónica de los muy altos y esclarecidos don Fernando y doña Isabel (ed. cit., p. 722: "Segunda Elisabeth continentis, fue muy feroz y enemiga de los malos e malas mugeres"), Tercera para Antonio de Nebrija ("A la muy alta y así esclarecida princesa doña Isabel la tercera de este nombre", Gramática, ed. de Pascual Galindo Romero y Luis Ortiz Muñoz, Madrid, 1946, t. 2, p. 3) y Séptima para la Breve suma de la santa vida del reverendisimo $i$ bienaventurado don fray Fernando de Talavera (Real Academia de la Historia, ms. C-114, fol. 142 v": "Buscando la reyna nuestra sennora donna Ysabel, séptima deste nombre, de gloriosa memoria..."). Agradecemos el último texto a don Francisco Márquez Villanueva. 
des históricas, y claves valiosas para entender aspectos y tendencias de obras y autores.

Antes de la Primera crónica general se utilizan sobrenombres para distinguir a los reyes homónimos. El Rey Sabio introduce en Castilla el numeral diferenciador. La serie alfonsí, que trata de abarcar el mayor número posible de soberanos, representa, en cierto modo, a toda la monarquía española, así como el León y la Castilla a los que Alfonso se refiere se identifican a menudo con la totalidad hispana.

La numeración alfonsí, que comienza a desaparecer a finales del xIv, vuelve a entrar en vigor en los últimos decenios del xv. Gracias a ella es fácil al Rey Católico introducirse en la serie de los Fernandos de Castilla. Después, aunque se encuentra hasta el xviII, raramente la utilizan los historiadores.

Las series que a lo largo del xv suplantan a la alfonsí coinciden en el propósito de separar a Castilla de todo lo que le sea ajeno. Ahora no interesa abarcar, sino excluir. Y según como se sienta a Castilla, las nuevas numeraciones olvidarán a los monarcas de ciertos períodos o de ciertos estados.

Para el canciller López de Ayala y para su sobrino Fernán Pérez de Guzmán, Castilla es la heredera del reino visigótico, del asturiano y del asturiano-leonés. Los otros estados españoles subrayan con sus diferencias la personalidad de Castilla. Así la numeración del canciller y del señor de Batres admiten únicamente a los reyes asturianos, asturiano-leoneses y castellanos.

Para Alfonso de Cartagena el reino de Castilla, uno de los más antiguos de Europa, es el primero entre los de la "nación española" el que la encabeza y la dirige. Castilla se ha ido haciendo y delineando con la suma y la reunión de todos los estados que ahora componen su variada realidad. La numeración del obispo de Burgos, también amplia y variada, olvida al aragonés Alfonso el Batallador.

Juan de Mena en el Laberinto canta la gloria de Castilla. Castilla, desligada de los otros reinos peninsulares, ajena a León, procede de Asturias, y con Asturias del imperio visigótico. Sus reyes (visigodos, astures, castellanos) han hecho posible el glorioso momento de Juan II.

A finales del xvi (demasiado lejos, por una parte, de la época en que Castilla trataba de definirse y diferenciarse de los otros reinos españoles; y ya demasiado cerca de la unión de los distintos estados peninsulares), los historiadores se preocupan especialmente de presentar a Castilla formando un todo con León y con Asturias. Así lo muestran en las numeraciones que utilizan.

En el siglo xvin el padre Flórez, decidido a eliminar la confusión que las varias numeraciones plantean, construye una nueva serie con la que trata de ser exacto y preciso. 
Así pues, a partir del momento en que el rey Alfonso de Castilla introduce en sus crónicas el nuevo método diferenciador, los escritores castellanos (poetas, historiadores, moralistas...) desde las más diferentes ocupaciones lo aprovechan gustosos para exponer y explicar de qué modo y bajo qué forma entienden y sienten a Castilla. El reino castellano, heredero siempre del tan llorado imperio visigótico, siempre acaudillando y dirigiendo a los otros reinos hermanos, comienza y continúa durante largos siglos la tarea gloriosa de la reconquista. Para unos Castilla es antigua, con una antigüedad tan fabulosa que sobrepasa con mucho la de los más remotos héroes mitológicos: para otros, en cambio, Castilla es joven, y es fácil señalar exactamente su nacimiento. Poetas hay que la presentan investida de innumerables virtudes que generosamente derramó sobre ella la mano de Dios; otros la circundan del esplendor ganado con su esfuerzo, sola y en pugna con todo lo que no sea ella misma. A lo largo de la Edad Media se levantan frecuentemente voces satisfechas de historiadores que anuncian o confirman el fin tan deseado de la reconquista; a menudo también, voces angustiadas se refieren con desánimo al presente. Pero para todos (poetas, cronistas, políticos) Castilla camina, rápida o lentamente, con energía o con cansancio, hacia un destino glorioso. Ante la mirada de los castellanos se abre la perspectiva segura de las promesas y de las profecías; y en su recuerdo, como testimonio indudable, se levantan los nombres heroicos de los Sanchos, de los Fernandos, de los Alfonsos.

University of California, Riverside.

Joaquín Gimeno Casalduero 